\title{
Oxovanadium(IV) complexes with [ONNO]-chelating ligands as catalysts for ethylene homo- and copolymerization
}

\author{
Marzena Bialek • Anna Leksza • Anna Piechota • \\ Krzysztof Kurzak $\cdot$ Katarzyna Koprek
}

Received: 25 November 2013 / Accepted: 13 February 2014 /Published online: 11 March 2014

(C) The Author(s) 2014. This article is published with open access at Springerlink.com

\begin{abstract}
Oxovanadium(IV) complexes with [ONNO]-type tetradentate Schiff base ligands: salen, acacen, aceten, acetph $\left(\mathrm{H}_{2}\right.$ salen $=\mathrm{N}, \mathrm{N}^{\prime}$-ethylenebis( salicylideneimine $)$, $\mathrm{H}_{2}$ aceten $=\mathrm{N}, \mathrm{N}^{\prime}$-ethylenebis(2-hydroxyacetophenoneimine), $\mathrm{H}_{2}$ acacen $=\mathrm{N}, \mathrm{N}^{\prime}$-ethylenebis(acetylacetonimine),

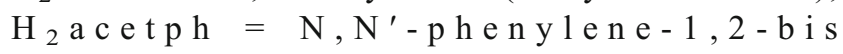
(2-hydroxyacetophenoneimine)), were the first time investigated in ethylene polymerization and ethylene/1-octene copolymerization processes. In general, all these complexes are moderately active precatalyst for ethylene polymerization upon activation with $\mathrm{EtAlCl}_{2}$ and they give high molecular weight linear polyethylenes. Their activity in copolymerization was found relatively low. However, they yielded copolymers with high 1-octene incorporation even at low comonomer concentrations in the feed. The catalytic performance in homo- and copolymerization was influenced by both the ligand structure and polymerization parameters (Al/ $\mathrm{V}$ molar ratio, polymerization temperature, comonomer feed concentration). In addition, the [VO(acacen)] was supported onto magnesium supports, and in the presence of various cocatalyst and at different reaction conditions it was screened as the catalyst of choice for ethylene homo- and copolymerization.
\end{abstract}

Keywords Oxovanadium(IV) complexes $\cdot$ Schiff base ligands · Polyolefins · Ziegler-Natta polymerization · Copolymerization

M. Białek $(\bowtie) \cdot$ A. Leksza $\cdot$ A. Piechota

Department of Chemical Technology and Polymer Chemistry, Faculty of Chemistry, Opole University,

Oleska 48, 45-052 Opole, Poland

e-mail: marzena.bialek@uni.opole.pl

K. Kurzak $\cdot$ K. Koprek

Faculty of Chemistry, Opole University,

Oleska 48, 45-052 Opole, Poland

\section{Introduction}

Polyethylene (HDPE) and ethylene/1-olefin copolymers (LLDPE) produced by transition metal-catalyzed coordination polymerization are classified as the most important synthetic polymers. The literature reflects the continued interest in catalysts for homo- and copolymerization of ethylene. Recently, after intensive exploration of metallocene and nonmetallocene group 4 complexes in these processes, the considerable attention is attracted by the catalysts of group 5 elements [1-5]. The vanadium complexes make an attractive goal for formulators in view of the fact that the classical vanadium catalysts display the unique characteristic as compared to the titanium-based ones. They allow to produce (i) high molecular weight polymers with narrow molecular weight distributions, (ii) high molecular weight amorphous ethylene/propylene copolymers, (iii) syndiotactic propylene [1,3]. The weak point of such vanadium catalysts is their rather quick deactivation during polymerization as a result of reduction of catalytically active vanadium species to inactive vanadium(II) species [6-8]. Adding chelating ligands to the vanadium compound can assist in stabilizing the vanadium species at a high state of oxidation. In addition, the structure of a ligand can be changed to modify the electronic and steric environment around the metal center, i.e. to modify the catalytic properties of the final vanadium complex.

Numerous vanadium complexes have been synthesized with a broad range of ligands and with variety of oxidation states of their metallic centers. For instance, mono- and bis(phenoxy-imine) vanadium complexes are highly active in ethylene polymerization but they are thermally unstable when the process is carried out at higher temperatures [9]. This problem though can be dissolved by using $\mathrm{MgCl}_{2} /$ $\mathrm{Et}_{\mathrm{m}} \mathrm{Al}(\mathrm{OR})_{\mathrm{n}}$ systems which serve as cocatalysts and supports 
at the same time [9]. A better thermal stability of vanadium complexes was obtained by using tridentate Schiff base ligands with pendant donors [10]. These complexes also offer the high ability to incorporate cyclic and linear olefins. Vanadium(III) complexes having bis(benzimidazole)amine ligands activated with common alkylaluminium compounds also turned out to be thermally robust and highly active single site catalysts for olefin polymerization and copolymerization [11]. A good thermal stability can also be expected from single-site catalysts which are based on bis(imino)pyrrolyl vanadium (III) complexes [ 12 ]. Mono ( $\beta$-enaminoketonato)vanadium(III) complexes show high catalytic activities in ethylene polymerization and an excellent capacity to copolymerize ethylene and 1-olefins or cycloolefins [13], while vanadium(III) complexes with iminopyrrolide ligands [14] or tridentate phenoxy-phosphine ligands [15] exhibit high activity in ethylene polymerization even at $70{ }^{\circ} \mathrm{C}$, and they can also efficiently catalyze the copolymerization process of ethylene with 10-undecen-1-ol to produce copolymers with around $15 \mathrm{~mol} \%$ of comonomer. (Arylimido)(aryloxo)vanadium(V) complexes show high activity in ethylene polymerization and a good potential to incorporate the norbornene monomer [16]. There were also reports published on vanadyl complexes which bear chelating aryloxide ligands and which demonstrate exceptionally high activities in ethylene polymerization [17].

The study regarding [ONNO]-type amine bis(phenolate) based vanadium(II-V) catalysts showed again that the $\mathrm{V}$ (II) state was inactive in ethylene polymerization. The catalytic activity and quality of the polyethylene products were found similar for the complexes with the oxidation states +5 to +3 which suggests the presence of similar catalytically active species in those systems [18]. For vanadyl phenoxyimine and vanadyl polyphenolate complexes, in turn, the vanadium(IV) species can be the active ones since their concentration correlates with the ethylene polymerization activity $[19,20]$.

The information is also vital that the majority of vanadium complexes shows a better activity in combination with simple alkylaluminium compounds, especially $\mathrm{EtAlCl}_{2}$ and $\mathrm{Et}_{2} \mathrm{AlCl}[10,12-18,21]$, which makes them good alternatives for MAO activated zirconium and titanium-based catalysts.

We recently reported that salen-type complexes of vanadium(IV) dichloride were efficient ethylene polymerization catalysts, especially after immobilization on the magnesium support $[22,23]$. In this paper we present the catalytic properties of oxovanadium(IV) complexes bearing salen-type and other tetradentate Schiff base ligands. They were used for ethylene homopolymerization and for ethylene/1-octene copolymerization.

\section{Experimental}

General procedures and materials

All air and moisture sensitive compounds were handled under the argon atmosphere, with the use of the standard Schlenk and glove box techniques. Ethylene (3.0 grade, Linde Gas) was used in tests after having been passed through a column packed with sodium metal supported on $\mathrm{Al}_{2} \mathrm{O}_{3}$. Toluene was distilled from sodium before use. 1-Octene from Aldrich was dried over molecular sieves 4A. Argon (5.0 grade, Linde Gas) and $\mathrm{EtAlCl}_{2}$ (25 wt \%, Aldrich) were used without further purification.

FT-IR spectra of polymeric products were recorded using the Nicole Nexus, 2002 FT-IR spectrometer. The copolymer samples were pressed into discs with $\mathrm{KBr}$ and 20 scans were taken in the range from $4,000 \mathrm{~cm}^{-1}$ to $400 \mathrm{~cm}^{-1}$ with a $2 \mathrm{~cm}^{-1}$ resolution. The compositions of copolymers were determined using the $A_{1379} / A_{1368}$ absorbance ratios obtained by separation of analytical bands [24]. The ${ }^{13} \mathrm{C}$ NMR spectra of the copolymers were recorded on the Ultrashield Bruker $400 \mathrm{MHz}$ spectrometer in 1,2-dichlorobenzene- $\mathrm{d}_{4}$ at $120^{\circ} \mathrm{C}$. The number of scans performed for each spectrum was at least 13,300. The chemical shifts were referenced internally to the major backbone methylene carbon resonance which was taken to be $30.00 \mathrm{ppm}$. The average molecular weights $\left(\mathrm{M}_{\mathrm{w}}\right)$ and molecular weight distributions $\left(M_{w} / M_{n}\right)$ were determined by gel permeation chromatography using the Alliance $135 \mathrm{GPCV}$ 2000 apparatus equipped with three columns: HT3, HT4 and HT6E. The measurements were performed at $135^{\circ} \mathrm{C}$, with 1,2,4-trichlorobenzene as the solvent, and at the flow rate of $1.0 \mathrm{ml} / \mathrm{min}$. The narrow molecular weight distribution polystyrene standards in the rage from $580 \mathrm{~g} / \mathrm{mol}$ to $3,000,790 \mathrm{~g} /$ mol were used for calibration. DSC analyses were carried out with the use of the 2010 DSC calorimeter from TA Instruments. The heat of fusion $\left(\Delta \mathrm{H}_{\mathrm{f}}\right)$ and melting point $\left(\mathrm{T}_{\mathrm{m}}\right)$ data were measured for samples which had been previously melted and recrystallized at the heating rate of $10{ }^{\circ} \mathrm{C} / \mathrm{min}$. Based on $\Delta \mathrm{H}_{\mathrm{f}}$, percentage of crystallinity was calculated as $\mathrm{X}_{\mathrm{c}}=\Delta \mathrm{H}_{\mathrm{f}} \times(100 / 290)$ [25]. The SSA fractionation was performed with the use of the same apparatus and according to the principles described earlier [26]. Initially, the samples were heated to $170{ }^{\circ} \mathrm{C}$ at the rate of $10{ }^{\circ} \mathrm{C} / \mathrm{min}$ and maintained at this temperature for $5 \mathrm{~min}$. Then, they were cooled down to $0{ }^{\circ} \mathrm{C}$. Heating-annealing-cooling cycles were repeated for temperatures: $125,119,114,111,107$ and $103{ }^{\circ} \mathrm{C}$.

Synthesis of vanadium complexes

Oxovanadium complexes used in this study were obtained in the reaction of a Schiff base with a salt or oxovanadium(IV) complex, according to [27]. 
[VO(salen)] A hot solution of vanadium(III) acetylacetonate $(2.089 \mathrm{~g}, 0.006 \mathrm{~mol})$ in $50 \mathrm{ml} \mathrm{MeOH}$ was added slowly to a hot solution of $1.609 \mathrm{~g}(0.006 \mathrm{~mol})$ of $\mathrm{H}_{2}$ salen in $50 \mathrm{ml} \mathrm{MeOH}$ with fours drops of triethyldiamine. The reaction mixture was refluxed with stirring for $4 \mathrm{~h}$ and then it was held at room temperature for $12 \mathrm{~h}$. The resulting precipitate was recovered by filtration, washed with cold methanol and recrystallized from $\mathrm{MeOH} / \mathrm{CHCl}_{3}$. Small green crystals were obtained. The yield was $1.58 \mathrm{~g}(78.9 \%)$. Elemental analysis: $\mathrm{C}_{16} \mathrm{H}_{14} \mathrm{~N}_{2} \mathrm{O}_{3} \mathrm{~V}$ (333.2 g/mol), calcd. C 57.67, H 4.23, N 8.41; found C 57.35, H 4.37, N 8.04. FTIR: $v(\mathrm{~V}-\mathrm{N}) 461 \mathrm{~cm}^{-1}, v(\mathrm{~V}-\mathrm{O}) 384 \mathrm{~cm}^{-1}$, $v(\mathrm{~V}=\mathrm{O}) 989 \mathrm{~cm}^{-1}, v(\mathrm{C}=\mathrm{N}) 1,622 \mathrm{~cm}^{-1}, v(\mathrm{C}-\mathrm{O}) 1,300 \mathrm{~cm}^{-1}$.

[VO(aceten)] A hot solution of vanadium(III) acetylacetonate $(2.687 \mathrm{~g}, 0.01 \mathrm{~mol})$ in $100 \mathrm{ml} \mathrm{MeOH}$ was added slowly to a hot solution of $3 \mathrm{~g}(0.01 \mathrm{~mol})$ of $\mathrm{H}_{2}$ aceten with fours drops of triethyldiamine. The reaction mixture was refluxed with stirring for $1 \mathrm{~h}$. After cooling to room temperature, a green solid precipitated and it was recovered by filtration, washed with cold methanol and finally recrystallized from $\mathrm{MeOH}$. The yield was $2.93 \mathrm{~g}(81 \%)$. Elemental analysis: $\mathrm{C}_{18} \mathrm{H}_{18} \mathrm{~N}_{2} \mathrm{O}_{3} \mathrm{~V}$ (361.3 g/mol), calcd. C 59.84, H 5.02, N 7.75; found C 60.21, $\mathrm{H}$ 4.59, N 7.81. FTIR: $v(\mathrm{~V}-\mathrm{N}) 446 \mathrm{~cm}^{-1}, v(\mathrm{~V}-\mathrm{O})$ $333 \mathrm{~cm}^{-1}, v(\mathrm{~V}=\mathrm{O}) 972 \mathrm{~cm}^{-1}, v(\mathrm{C}=\mathrm{N}) 1,583 \mathrm{~cm}^{-1}, v$ (C-O) $1,325 \mathrm{~cm}^{-1}$.

[VO(acetph)] A hot solution of oxovanadium(IV) sulfate(VI) $(2.37 \mathrm{~g}, 0.0145 \mathrm{~mol})$ in $120 \mathrm{ml} \mathrm{MeOH}$ was added slowly to a hot solution of $4.99 \mathrm{~g}$, $(0.0145 \mathrm{~mol})$ of $\mathrm{H}_{2}$ acetph in $200 \mathrm{ml}$ $\mathrm{MeOH}$ with an admixture of triethylamine $(1 \mathrm{ml})$. The reaction mixture was refluxed with stirring for $4 \mathrm{~h}$. After cooling, a brown solid precipitated which was recovered by filtration and then washed with cold methanol and finally recrystallized from $\mathrm{MeOH}$. The yield was $3.9 \mathrm{~g}(65.7 \%)$. Elemental analysis: $\mathrm{C}_{22} \mathrm{H}_{18} \mathrm{~N}_{2} \mathrm{O}_{3} \mathrm{~V}$ (409.3 g/mol), calcd. C 64.55, H 4.43, N 6.84; found $\mathrm{C}$ 64.31, $\mathrm{H} \mathrm{4.31,N} \mathrm{6.62.} \mathrm{FTIR:} v(\mathrm{~V}-\mathrm{N}) 532 \mathrm{~cm}^{-1}$, $v(\mathrm{~V}-\mathrm{O}) 367 \mathrm{~cm}^{-1}, v(\mathrm{~V}=\mathrm{O}) 979 \mathrm{~cm}^{-1}, v(\mathrm{C}=\mathrm{N}) 1,584 \mathrm{~cm}^{-1}$, $v(\mathrm{C}-\mathrm{O}) 1,333 \mathrm{~cm}^{-1}$.

[VO(acacen)] The [VO(acacen)] complex was synthesized as described in [28]. The Schiff base ligand, $\mathrm{H}_{2}$ acacen $(2.2 \mathrm{~g}$, $0.01 \mathrm{~mol}$ ), was added to bis(2,4-pentanediono)vanadyl(IV) $(2.7 \mathrm{~g}, 0.01 \mathrm{~mol})$ and the obtained mixture was heated at $240{ }^{\circ} \mathrm{C}$ under reduced pressure (about $5 \mathrm{mbar}$ ) for $1.5 \mathrm{~h}$. The solid product was washed with ether and then it was extracted with hot toluene. The hot extract was filtered, cooled and left for crystallization at $5^{\circ} \mathrm{C}$ for $12 \mathrm{~h}$. The resulting blue-green crystals were recovered by filtration, washed with cold ether, dried and recrystallized from toluene. The yield was $1.56 \mathrm{~g}$ (53.8 \%). Elemental analysis: $\mathrm{C}_{12} \mathrm{H}_{18} \mathrm{~N}_{2} \mathrm{O}_{3} \mathrm{~V}$ (289.2 g/mol), calcd. C 49.83, H 6.27, N 9.69; found C 50.05, H 6.21, N 9.68. FTIR: $v(\mathrm{~V}-\mathrm{N}) 421 \mathrm{~cm}^{-1}, v(\mathrm{~V}-\mathrm{O}) 364 \mathrm{~cm}^{-1}, v(\mathrm{~V}=\mathrm{O})$ $979 \mathrm{~cm}^{-1}, v(\mathrm{C}=\mathrm{N}) 1,584 \mathrm{~cm}^{-1}, v(\mathrm{C}-\mathrm{O}) 1,287 \mathrm{~cm}^{-1}$.
Synthesis of supported catalysts

Cat-S1 $\left\{[\mathrm{VO}\right.$ (acacen) $\left.] / \mathrm{MgCl}_{2}(\mathrm{THF})_{2} / \mathrm{Et}_{2} \mathrm{AlCl}\right\} 6.9 \mathrm{mg}$ of $[\mathrm{VO}($ acacen $)]$ in toluene was added to the suspension of $1.059 \mathrm{~g}$ of $\mathrm{MgCl}_{2}(\mathrm{THF})_{2} / \mathrm{Et}_{2} \mathrm{AlCl}$ [23] in hexane and then the mixture was ball milled, at room temperature, at the fixed rotational speed of $80 \mathrm{rev} . / \mathrm{min}$, for $20 \mathrm{~h}$. The solid material was separated, washed several times with toluene and hexane and then dried until free-flowing. The filtrate was colorless from the very beginning which showed that the whole amount of the complex used had been completely immobilized. The yield was $0.7222 \mathrm{~g}$. The AAS analysis indicated that the Cat$\mathbf{S 1}$ contained $1.66 \mathrm{mg}$ of $\mathrm{V} / \mathrm{g}, 41.4 \mathrm{mg}$ of $\mathrm{Al} / \mathrm{g}$ and $19.8 \mathrm{mg}$ of $\mathrm{Mg} / \mathrm{g}$, which confirms immobilization of the total amount of the vanadium complex in practice. The synthesis was repeated twice.

Cat-S2 $\left\{[\mathrm{VO}\right.$ (acacen) $\left.] / \mathrm{MgCl}_{2}(\mathrm{EtOH})_{3.6} / \mathrm{Et}_{2} \mathrm{AlCl}\right\}$ The supported catalyst was obtained by ball milling of the magnesium support $\mathrm{MgCl}_{2}(\mathrm{EtOH})_{3.6} / \mathrm{Et}_{2} \mathrm{AlCl}, 1.872 \mathrm{~g}$ (synthesized according to [29]) and vanadium complex [VO(acacen)], $0.0120 \mathrm{~g}$, in hexane/toluene, at room temperature, at the fixed rotational speed of $80 \mathrm{rev} . / \mathrm{min}$, for $20 \mathrm{~h}$. Then the solid was separated by filtration, washed with toluene $(14 \mathrm{ml})$ and with hexane $(50 \mathrm{ml})$. Finally, it was dried until free-flowing. The filtrate was colourless from the very beginning which showed that the whole amount of the complex used had been completely immobilized. The yield was $1.265 \mathrm{~g}$.

\section{General procedure for ethylene polymerization}

Ethylene polymerization was carried out in a Büchi glass autoclave equipped with the magnetic stirrer and heating-cooling jacket. The reactor was charged with $150 \mathrm{ml}$ of toluene, the required amount of activator and the vanadium complex. Finally, the ethylene gas was fed. The ethylene feed pressure (5 atm) and the reactor temperature were kept constant throughout the runs. After the prescribed time, $30 \mathrm{~min}$, the ethylene gas feed was stopped and methanol was added to terminate the reaction. The obtained mixture was poured in to a dilute solution of hydrochloric acid in methanol. The polymer was filtered, washed a few times with methanol and dried in vacuo.

General procedure for ethylene/1-octene copolymerization

The ethylene/1-octene copolymerization followed the same procedure as ethylene homopolymerization and the only difference was that 1-olefin was charged to the reactor after a solvent had been added there. 


\section{Results and discussion}

The study involved four oxovanadium(IV) complexes with different structures of the [ONNO]-chelating ligand (Scheme 1). Three of them: [VO(salen)], [VO(aceten)], [VO(acacen)] were green and had five-membered N-N chelate rings which can be indicative for their monomeric structures with the five-coordinate square-pyramidal geometry [30]. Moreover, all they showed $\mathrm{V}=\mathrm{O}$ stretching bands at around $970 \mathrm{~cm}^{-1}$ which proved their monomeric forms [30]. Indeed, previous characterization of [ $\mathrm{VO}($ salen $)]$ and $[\mathrm{VO}$ (acacen) $]$ by $\mathrm{X}$-ray crystallography shown that they exhibit the squarepyramidal coordination [31,32].

The last investigated complex, [VO(acetph)], was colored brown and shows the $\mathrm{V}=\mathrm{O}$ stretching bond at $979 \mathrm{~cm}^{-1}$. Crystals of [VO(acetph)] suitable for the X-ray crystal structure analysis were grown from methanol and they were green. Analysis confirmed that the central V(IV) site in green [VO(acetph)] complex had a distorted square-pyramidal coordination. Two $\mathrm{N}$ atoms and two $\mathrm{O}$ atoms of the Schiff base ligand define the base of the pyramid, and the oxide $\mathrm{O}$ atom is located in the apical position [33].

Ethylene polymerization by $\left[\mathrm{V}^{\mathrm{IV}} \mathrm{OL}\right] / \mathrm{EtAlCl}_{2}$ catalytic systems

Prior to their use in the polymerization reaction, oxovanadium complexes with [ONNO]-ligands have to be activated by an alkylaluminium compound to form the M-alkyl bond and the coordination site for an olefin. The activator can react by attacking on the $\mathrm{V}=\mathrm{O}$ bond, as it was suggested for oxovanadium $(\mathrm{V})$ complexes with the strongly coordinated tetradentate calix[4]arene ligand [19] or, as it was postulated for vanadium bis(phenoxyimine) complexes, by replacing the ligand with an alkyl-anion [20].

The catalytically active vanadium sites are known for their low stability in olefin polymerization due to their reduction to low-valence species. To overcome that problem, olefin

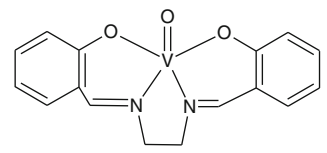

[VO(salen)]

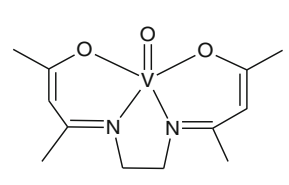

[VO(acacen)]

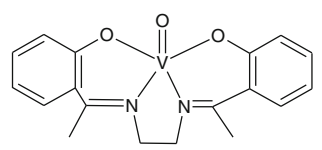

[VO(aceten)]

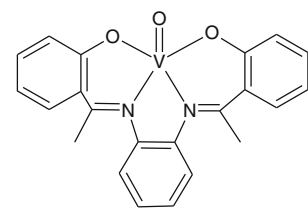

[VO(acetph)]
Scheme 1 Oxovanadium(IV) complexes used in present work polymerization processes are often run in the presence of a promoter, halogenated hydrocarbons or halocarbon esters like $\mathrm{Cl}_{3} \mathrm{CCOOEt}[3,12]$. Another method is based on the use of an activator with a lower reduction potential. Earlier reports [18, $22]$ indicate that salen complexes of vanadium dichloride and vanadium complexes with diamino-bis(phenolate) ligands give higher polymerization activities in conjunction with chloroalkylaluminium compounds, especially with $\mathrm{EtAlCl}_{2}$. It was also shown that active species in the catalysts which contain oxovanadium complexes are formed only after their activation with a chlorine atom-containing alkylaluminium compound and vanadium is in an oxidation state of +4 in them $[19,20]$. Therefore, ethylene polymerization processes in the presence of oxovanadium complexes were conducted in toluene with $\mathrm{EtAlCl}_{2}$ as an activator.

All complexes upon activation proved to be active in ethylene polymerization. The typical results as summarized in Table 1 indicate that the studied complexes display different catalytic activities under the same conditions. The activity at the $\mathrm{Al} / \mathrm{V}$ molar ratio equal to $129(1.8 \mathrm{mmol}$ of activator in the polymerization feed) increase for the following sequence of the catalysts: $[\mathrm{VO}($ salen $)]<[\mathrm{VO}($ acetph $)]<[\mathrm{VO}($ aceten $)]<$ $[\mathrm{VO}$ (acacen) $]$. The catalyst $[\mathrm{VO}$ (acacen) $] / \mathrm{EtAlCl}_{2}$ shows the highest activity also at $\mathrm{Al} / \mathrm{V}=385 \mathrm{~mol} / \mathrm{mol}(5.4 \mathrm{mmol}$, entry 23). All the catalysts produce linear polyethylene (which was confirmed by their FTIR spectra) with the melting temperature in the rage $135-140{ }^{\circ} \mathrm{C}$ and with high molecular weight.

Not only the ligand structures but also the $\mathrm{Al} / \mathrm{V}$ molar ratio considerably influences the polymerization behaviour of the catalytic complexes. The activity of [VO(aceten)] (Table 1, entry 28 and 12) and of [VO(acacen)] (Table 1, entry 25, 21 and 23) decrease with the increase of the $\mathrm{Al} / \mathrm{V}$ molar ratio from 129 to 386 . The inverse relation can be observed for [VO(salen)], i.e. increasing $\mathrm{Al} / \mathrm{V}$ molar ratio up to 386 results in better catalytic activity (entry 32 and 6). However, any further increase in the ratio (entry 9) reduces the catalyst productivity. The temperature effect on the catalytic activity was evaluated for the same complex at the $\mathrm{Al} / \mathrm{V}$ molar ratio equal to 514 (Table 1, entry 6 and 7). As can be seen, the catalytic system based on the oxovanadium complex bearing a salen ligand did not offer a good thermal stability, just alike salen complexes of vanadium(IV) dichloride reported by us earlier [22].

The polymerization conditions, the $\mathrm{Al} / \mathrm{V}$ molar ratio and polymerization temperature, also significantly influenced the polymer properties. The molecular weights were decreased for the increasing $\mathrm{Al} / \mathrm{V}$ molar ratio. The increase of $\mathrm{Al} / \mathrm{V}$ from 129 to 386 and to 514 changed the molecular weight of polyethylene produced by [VO(salen)] from $539,000 \mathrm{~g} / \mathrm{mol}$ to $458,000 \mathrm{~g} / \mathrm{mol}$ and to $250,000 \mathrm{~g} / \mathrm{mol}$, respectively. The same effect was observed for polymers synthesized by $\left[\mathrm{VO}\right.$ (acacen)]/EtAlCl$l_{2}$ (Table 1, entry 25 and 23). These results indicate that the chain transfer to the alkylaluminium 
Table 1 Ethylene polymerization catalyzed by different oxovanadium complexes activated by $\mathrm{EtAlCl}_{2}$

\begin{tabular}{|c|c|c|c|c|c|c|c|c|}
\hline Entry & Catalyst & Activator (mmol) & Yield (g) & Activity $\left(\mathrm{kg}_{\mathrm{PE}} / \mathrm{mol}_{\mathrm{V}}\right)$ & $\mathrm{T}_{\mathrm{m}}\left({ }^{\circ} \mathrm{C}\right)$ & $\chi(\%)$ & $\mathrm{M}_{\mathrm{w}} \cdot 10^{-3}(\mathrm{~g} / \mathrm{mol})$ & $\mathrm{M}_{\mathrm{w}} / \mathrm{M}_{\mathrm{n}}$ \\
\hline 32 & [VO(salen)] & 1.8 & 0.495 & 35.4 & 140.4 & 54 & 539 & 3.2 \\
\hline 7 & {$[\mathrm{VO}(\text { salen })]^{\mathrm{a}, \mathrm{b}}$} & 3.6 & 0.454 & 64.9 & 139.3 & 56 & 193 & 5.9 \\
\hline 6 & {$[\mathrm{VO}(\text { salen})]^{\mathrm{a}}$} & 3.6 & 0.680 & 97.1 & 137.5 & 50 & 741 & 3.0 \\
\hline 9 & [VO(salen)] & 5.4 & 1.798 & 128.4 & 139.0 & 50 & 458 & 3.8 \\
\hline 8 & [VO(salen)] & 7.2 & 1.180 & 84.3 & 135.6 & 50 & 250 & 6.1 \\
\hline 28 & [VO(aceten)] & 1.8 & 1.926 & 137.6 & 136.4 & 58 & 596 & 3.7 \\
\hline 12 & [VO(aceten)] & 5.4 & 1.521 & 108.6 & 142.1 & 45 & nd & nd \\
\hline 25 & [VO(acacen)] & 1.8 & 3.740 & 267.1 & 139.9 & 53 & 636 & 4.4 \\
\hline 21 & [VO(acacen)] & 3.6 & 2.794 & 199.6 & 138.2 & 61 & nd & nd \\
\hline 23 & [VO(acacen)] & 5.4 & 2.096 & 149.7 & 137.2 & 60 & 426 & 4.6 \\
\hline 30 & [VO(acetph)] & 1.8 & 1.096 & 78.3 & 137.3 & 59 & 510 & 4.7 \\
\hline
\end{tabular}

Reaction conditions: $0.014 \mathrm{mmol}$ of catalyst, $5 \mathrm{~atm}$ of ethylene, $30 \mathrm{~min}, 30{ }^{\circ} \mathrm{C}$

nd not determned

${ }^{\mathrm{a}} 0.007 \mathrm{mmol}$ catalyst

${ }^{\mathrm{b}} 50{ }^{\circ} \mathrm{C}$

compound was an important chain-transfer pathway under adopted conditions. The chain transfer reaction was enhanced at higher temperatures and polyethylene with lower molecular weight was formed at $50^{\circ} \mathrm{C}$ then at $30^{\circ} \mathrm{C}$ (Table 1 , entry 6 and 7). It is a result of higher activation energies for the chain transfer reactions then for the monomer insertions which affects the relative rate of chain transfer as compared to the rate of propagation [34]. In addition, the molecular weight distributions increase with the temperature increase.

The SEM micrographs of polyethylenes obtained with different oxovanadium(IV) complexes (Fig. 1) show that morphology of the polymer produced by [VO(acetph)] is different from those of other polyethylenes: the polymer in question had the form or flakes while other polyethylenes were obtained as irregular granules with diversified sizes.

\section{Ethylene/1-octene copolymerization by $\left[\mathrm{V}^{\mathrm{IV}} \mathrm{OL}\right] / \mathrm{EtAlCl}_{2}$ catalytic systems}

One of the most important grade of polyethylene, linear lowdensity polyethylene, is obtained by copolymerization of ethylene with $\alpha$-olefin and this process allows to control density and crystallinity of polyethylene. The presence of short-chain branches decreases the melting temperature and crystallinity of polymer because the comonomer units interfere with crystallization and reduce the size of crystallites [18]. The length of side chains is dependent on the type of $\alpha$-olefin and the number of those chains is dependent on the comonomer concentration in the feed and on the ability of the catalytic system to incorporate the comonomer. The ethylene/1-octene copolymerization tests with $\left[\mathrm{V}^{\mathrm{IV}} \mathrm{OL}\right] / \mathrm{EtAlCl}_{2}$ systems were run under the same conditions as described for ethylene homopolymerization, i.e. $30^{\circ} \mathrm{C}, 5 \mathrm{~atm}$ ethylene, $30 \mathrm{~min}$, and with different cocatalyst-to-complex ratios. The standard comonomer concentration was equal to $0.40 \mathrm{~mol} / \mathrm{dm}^{3}$ thought some experiments with other comonomer concentrations were also performed. The results can be seen in Table 2 .

All the catalysts lost some activity after introduction of 1octene. The increase in the 1-octene concentration reduced that activity even further. The activity of vanadium catalysts, when used in copolymerization at $\mathrm{Al} / \mathrm{V}=129 \mathrm{~mol} / \mathrm{mol}$ and at the comonomer concentration of $0.40 \mathrm{~mol} / \mathrm{dm}^{3}$ (Table 2, entry 33,31 and 26), was dependent on the ligand structure and that relation was the same as for ethylene homopolymerization
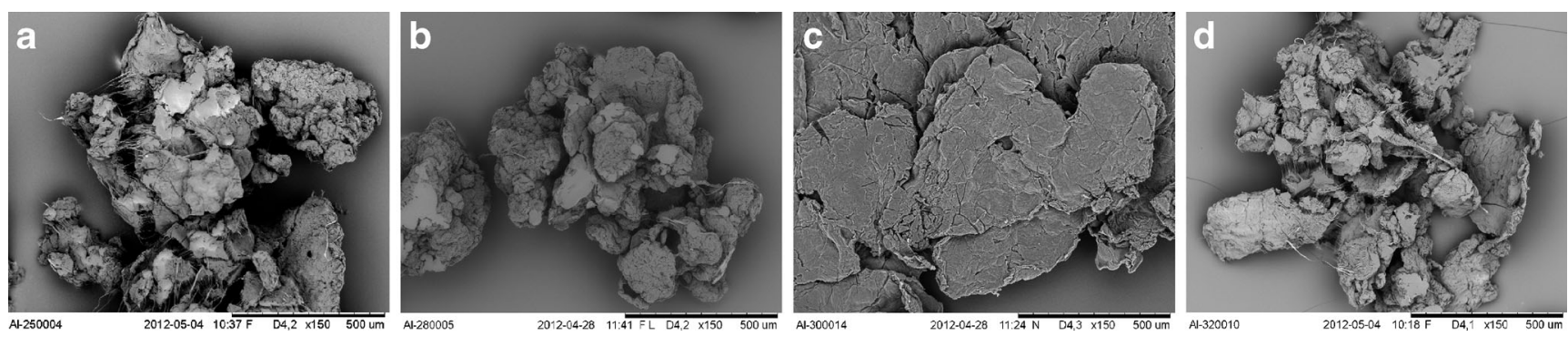

Fig. 1 SEM imagines of PE obtained with vanadium complexes; a) [VO(acacen)], b) [VO(aceten)], c) [VO(acetph)] and d) [VO(salen)]. Magnification $\times 150$ 
Table 2 Ethylene/1-octene copolymerization catalyzed by different oxovanadium complexes activated by $\mathrm{EtAlCl}_{2}$

\begin{tabular}{|c|c|c|c|c|c|c|c|c|c|c|}
\hline Entry & Catalyst & 1-Octene (ml) & $\begin{array}{l}\text { Activator } \\
\text { (mmol) }\end{array}$ & Yield (g) & $\begin{array}{l}\text { Activity } \\
\left(\mathrm{kg}_{\mathrm{PE}} / \mathrm{mol}_{\mathrm{V}}\right)\end{array}$ & $\begin{array}{l}\text { Octene content } \\
(\mathrm{mol} \%)\end{array}$ & $\mathrm{T}_{\mathrm{m}}\left({ }^{\circ} \mathrm{C}\right)$ & $x(\%)$ & $\mathrm{M}_{\mathrm{w}} \cdot 10^{-3}(\mathrm{~g} / \mathrm{mol})$ & $\mathrm{M}_{\mathrm{w}} / \mathrm{M}_{\mathrm{n}}$ \\
\hline 32 & [VO(salen)] & - & 1.8 & 0.495 & 35.4 & - & 140.4 & 54 & 539 & 3.2 \\
\hline 33 & [VO(salen)] & 10 & 1.8 & 0.037 & 2.6 & 6.25 & 111.7 & nd & nd & nd \\
\hline 9 & [VO(salen)] & - & 5.4 & 1.798 & 128.4 & - & 139.0 & 50 & 458 & 3.8 \\
\hline 11 & [VO(salen)] & 5 & 5.4 & 0.256 & 18.3 & 1.98 & 118.8 & nd & 547 & 3.7 \\
\hline 10 & [VO(salen)] & 10 & 5.4 & 0.194 & 13.9 & 4.33 & 111.3 & 29 & 576 & 6.6 \\
\hline 28 & [VO(aceten)] & - & 1.8 & 1.926 & 137.6 & - & 136.4 & 58 & 596 & 3.7 \\
\hline 29 & [VO(aceten)] & 5 & 1.8 & 1.287 & 91.9 & 0.52 & 133.1 & 54 & nd & nd \\
\hline 31 & [VO(aceten)] & 10 & 1.8 & 0.044 & 3.1 & 5.40 & 111.8 & 39 & nd & nd \\
\hline 25 & [VO(acacen)] & - & 1.8 & 3.740 & 267.1 & - & 139.9 & 53 & 636 & 4.4 \\
\hline 27 & [VO(acacen)] & 5 & 1.8 & 0.484 & 34.6 & 2.45 & 119.8 & 38 & 378 & 5.3 \\
\hline 26 & [VO(acacen)] & 10 & 1.8 & 0.253 & 18.1 & 5.26 & $\begin{array}{l}111.6 \\
124.6\end{array}$ & nd & 159 & 6.4 \\
\hline 23 & [VO(acacen)] & - & 5.4 & 2.096 & 149.7 & - & 137.2 & 60 & 426 & 4.6 \\
\hline 22 & [VO(acacen)] & 10 & 5.4 & 0.430 & 30.7 & 2.26 & 135.8 & 55 & 211 & 5.8 \\
\hline
\end{tabular}

Reaction conditions: $0.014 \mathrm{mmol}$ of catalyst, $5 \mathrm{~atm}$ of ethylene, $30 \mathrm{~min}, 30^{\circ} \mathrm{C}$

$n d$ not determned

$([\mathrm{VO}($ salen $)]<[\mathrm{VO}($ aceten $)]<[\mathrm{VO}($ acacen $)])$. However, the amount of polymer obtained from copolymerization was each time considerably lower than from homopolymerization, in most cases a few times lower. That high drop in the reaction yield may be indicative for a very high incorporation of 1octene. Indeed, in spite of a relatively low comonomer concentration in the polymerization feed, 1-octene incorporation to the polyethylene chain was very high and it amounted to $6.25,5.40$ and $5.26 \mathrm{~mol} \%$ for copolymers obtained with [VO(salen)], [VO(aceten)] and [VO(acacen)], respectively. Those results suggest that the methyl substituent at the carbon atom in the imine group affects the comonomer incorporation. The catalyst bearing the salen ligand showed the highest comonomer incorporation ability, probably due to lower steric hindrance caused by the hydrogen atom. The increase in comonomer concentration results also in higher comonomer incorporation (Table 2, entry 11 and 10,29 and 31,27 and 26).

The effect of the Al/V molar ratio on the copolymerization reaction was tested for the catalytic systems: [VO(salen)]/ $\mathrm{EtAlCl}_{2}$ (Table 2, entry 33, 10) and $\left[\mathrm{VO}\right.$ (acacen)]/EtAlCl ${ }_{2}$ (Table 2, entry 26, 22). It is seen that the comonomer incorporation is evidently lower at a higher cocatalyst/complex molar ratio than at a lower $\mathrm{Al} / \mathrm{V}$ ratio. Moreover, the results confirmed a better comonomer incorporation ability of the salen complex.

It can be seen in Table 2 and in Fig. 2 that the molecular weight of polyethylene obtained with $\left[\mathrm{VO}\right.$ (acacen)]/EtAlCl${ }_{2}$ is much higher than that for copolymers, and that it decreases with the increase of comonomer concentration in the feed. Such effects were observed repeatedly for copolymerizations catalyzed by different catalytic systems [21,35-38]. Lower molecular weights of polymers for increasing 1-octene concentrations may result from the chain transfer to comonomer and/or more favourable $\beta$-hydride elimination after comonomer incorporation. Besides, the presence of a comonomer and its increasing concentration lead to a broader distribution of molecular weights. And even an additional higher molecular weight fraction can be is observed on the MWD curve of copolymer with higher comonomer content (Fig. 2, curve 3) although its share is low. It is interesting that the difference between the molecular weights of polyethylene and copolymers synthesized with [VO(salen)] was slight only, and copolymers had even higher MW values than the homopolymer (Table 2, Fig. 3). It is not a typical situation, although a much higher molecular weight of copolymer than that of homopolymer was observed earlier for propylene/1-

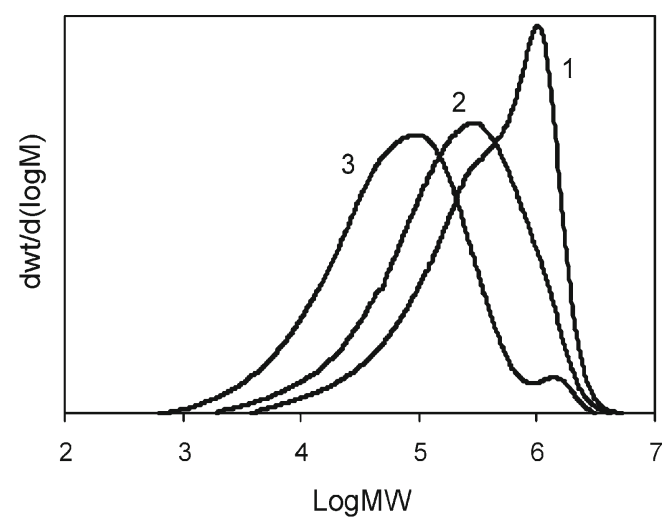

Fig. 2 GPC curves of polyethylene (1: PE 25) end ethylene/1-octene copolymers $(2$ : copolymer $27 ; 3$ : copolymer 26$)$ produced by $[\mathrm{VO}($ acacen $)] / \mathrm{EtAlCl}_{2}$ 


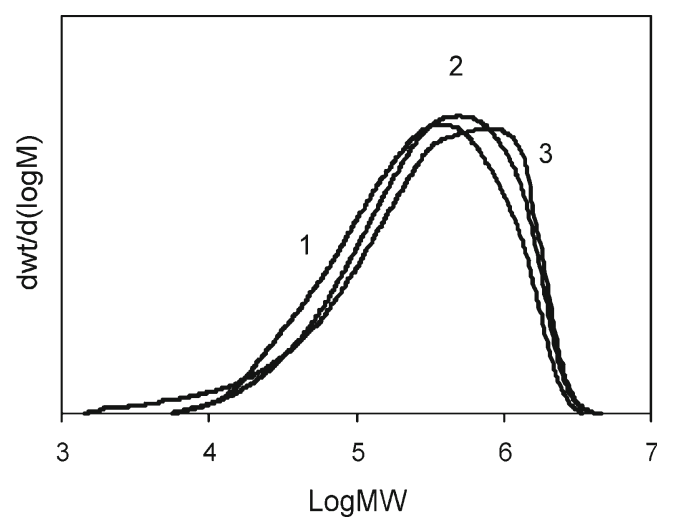

Fig. 3 GPC curves of polyethylene (1: PE 9) end ethylene/1-octene copolymers $(2$ : copolymer $10 ; 3$ : copolymer 11$)$ produced by $[\mathrm{VO}($ salen $)] / \mathrm{EtAlCl}_{2}$

octene copolymers and polypropylene synthesized with the metallocene catalyst [39].

The information on the polymer chain transfer reactions can be obtained from the data on the nature of double bounds in copolymers. The FTIR spectra show the same end groups in copolymers obtained with both catalysts. For copolymers 26 and 33 , synthesized with $[\mathrm{VO}$ (acacen) $] / \mathrm{EtAlCl}_{2}$ and $\left[\mathrm{VO}(\right.$ salen) $] / \mathrm{EtAlCl}_{2}$, respectively, the intensive absorption bands at 1,370 and $1,380 \mathrm{~cm}^{-1}$, which are specific for the groups $\mathrm{CH}_{3}$ and $\mathrm{CH}_{2}$, are accompanied by very low intensity bands which represent vibrations of the vinyl group (about $910 \mathrm{~cm}^{-1}$ ) and the bands for the vinylidene and trans-vinylene groups, at about $890 \mathrm{~cm}^{-1}$ and $967 \mathrm{~cm}^{-1}$, respectively (Fig. 4). The vinyl and vinylidene groups may be formed by $\beta$ hydrogen elimination or $\beta$-hydrogen transfer to the monomers with ethylene or with 1-octene (after 1,2-insertion) as a last inserted monomer. The trans-vinylidene terminal group is formed when a chain with 1-octene after 2,1-insertion is involved in the reaction as the last inserted monomer [40-42]. Hence, different effects of comonomer on molecular weights of copolymers produced over different catalytic systems do not result from different chain termination reactions but rather from different relations between the rates of chain propagation reactions and chain termination reactions.

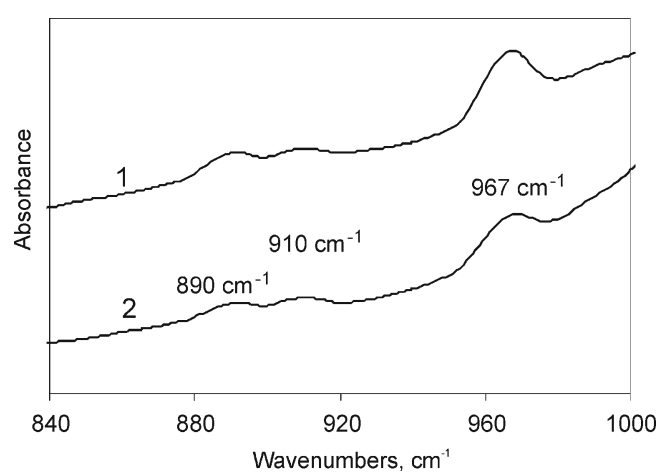

Fig. 4 FTIR spectra (in the range of 840 to $1,000 \mathrm{~cm}^{-1}$ ) of copolymers obtained with (1) $\left[\mathrm{VO}(\right.$ acacen) $] / \mathrm{EtAlCl}_{2}$, copolymer 26 and (2) $\left[\mathrm{VO}(\right.$ salen) $] / \mathrm{EtAlCl}_{2}$, copolymer 33
The effect of incorporation of 1-octene on melting behaviour of polymers produced by $[\mathrm{VO}$ (salen) $] / \mathrm{EtAlCl}_{2}$ and $[\mathrm{VO}$ (acacen) $] / \mathrm{EtAlCl}_{2}$ is shown in Figs. 5 and 6, respectively. The incorporation of comonomers shifts melting peaks of copolymers in relation to homopolymers towards lower temperatures. Very wide melting peaks can be observed in some thermograms, while other thermograms of 26 and 27 (Fig. 6) reveal not only principal melting peaks at $111^{\circ} \mathrm{C}$ and $126^{\circ} \mathrm{C}$, respectively, but also additional small peaks at $125^{\circ} \mathrm{C}$ and $138^{\circ} \mathrm{C}$, correspondingly. Those observations are indicative of heterogeneous comonomer distribution. One of the techniques used for characterization of short chain branching distribution in copolymers is the SSA technique (SSA - self-nucleation annealing) which is based on the sequential application of self-nucleation and annealing steps to polymer samples [26, 43]. We apply six self-nucleation and annealing steps with isothermal treatment at $125,119,114,111,107$ and $103{ }^{\circ} \mathrm{C}$. After the use of that procedure, the fractionated copolymers show a series of melting peaks which are consistent with the melting of different mean lamellar thickness crystallites formed and annealed at every temperature applied [43]. Figure 7 shows that four fractions were produced for 31 and 33 polymer samples at temperatures ranging from 98 to $114{ }^{\circ} \mathrm{C}$ and that their distribution was unimodal. The shapes of the DSC endotherms obtained for both copolymers are very similar to each other. The copolymer 26 obtained with [VO(acacen)] exhibited a higher number of melting peaks (six) with endotherm minimums ranging from 98 to $129^{\circ} \mathrm{C}$ and the distribution of melting peaks for this copolymer being bimodal. Though, the area under two high temperature peaks (with the minima at about $122{ }^{\circ} \mathrm{C}$ and $129{ }^{\circ} \mathrm{C}$ ), corresponding to higher lamellae thickness (and lower 1 -octene content), is small.

The microstructures of two selected poly(ethylene-co-1octene)s synthesized with [VO(salen)] and [VO(aceten)] were analyzed using ${ }^{13} \mathrm{C}$ NMR. The spectra of both copolymers were similar to each other, hence only the spectrum of the sample produced by $\left[\mathrm{VO}(\right.$ salen) $] / \mathrm{EtAlCl}_{2}$ is presented in Fig. 8. As can be seen, no resonances ranging from 40 to

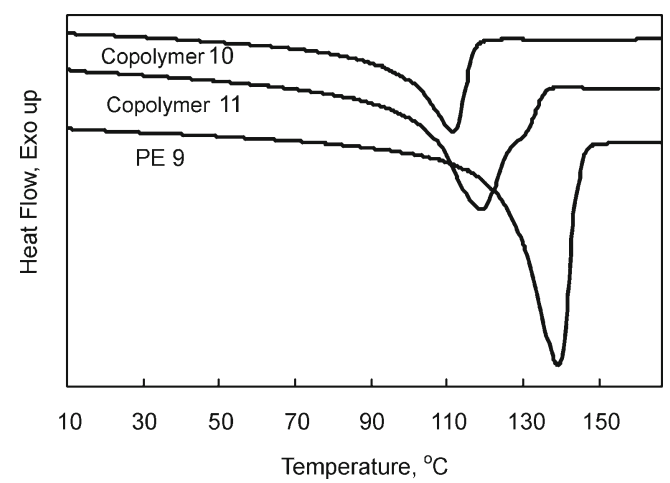

Fig. 5 DSC thermograms of polyethylene and ethylene/1-octene copolymers produced by $\mathrm{VO}$ (salen)/EtAlCl 2 


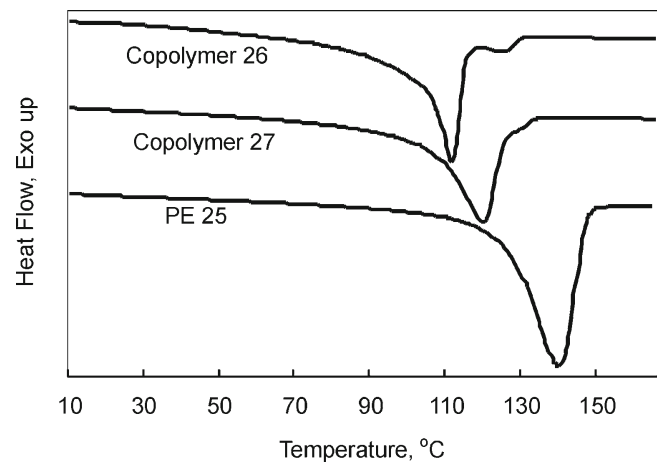

Fig. 6 DSC thermograms of polyethylene end ethylene/1-octene copolymers produced by $\mathrm{VO}$ (acacen)/EtAlCl 2

$42 \mathrm{ppm}$ for the $\alpha \alpha$-carbon in the block type sequence are present. This indicates that the octene units are isolated by ethylene units in the polymer chains. The resonance at about $25 \mathrm{ppm}$ for the $\beta \beta$-carbon in the alternative sequence is not present, either [35].

Ethylene homopolymerization and ethylene/1-octene copolymerization by supported catalysts which contain [VO(acacen)]

All oxovanadium complexes, irrespective of the ligand structures, turned out effective in the ethylene/1-octene copolymerization process. Copolymers with a very high content of 1olefin and essentially different properties in relation to ethylene homopolymer could be produced, even at low comonomer concentrations in the reaction medium. The possibility of using a lower amount of a costly comonomer to obtain the planned change(s) in the polyethylene properties makes that catalyst attractive from the viewpoint of commercial applications. Such complexes, however, have a disadvantage - very low activity. Improved activity of various generations of organometallic catalysts becomes available in many cases after anchoring such catalysts on a support. In our study, [VO(acacen)] was

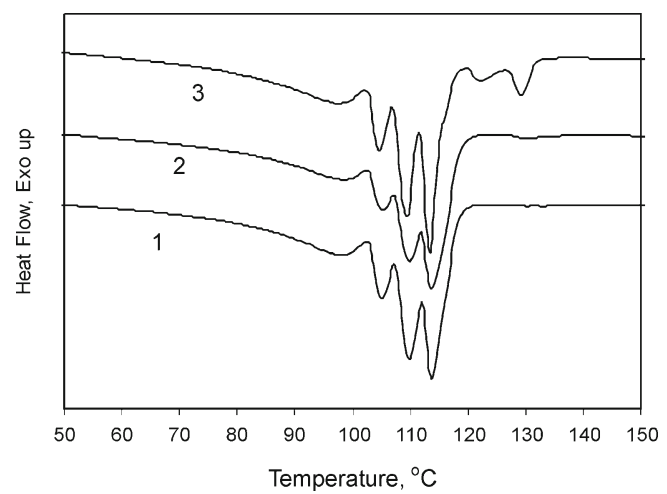

Fig. 7 DSC thermograms of ethylene/1-octene copolymers (1 - copolymer 33; 2-copolymer 31; 3-copolymer 26 synthesised with [VO(salen)], $[\mathrm{VO}($ aceten $)]$ and $[\mathrm{VO}$ (acacen)], respectively) after SSA thermal treatment

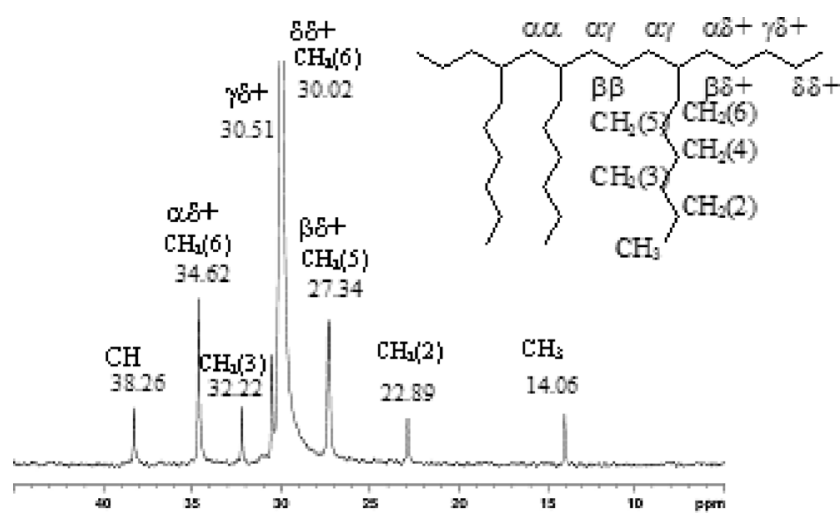

Fig. 8 The ${ }^{13} \mathrm{C}$ NMR spectrum of poly(ethylene-co-1-octene) obtained with $\left[\mathrm{VO}\right.$ (salen)]/EtAlCl${ }_{2}$, (copolymer 10, $4.33 \mathrm{~mol} \%$ )

chosen for immobilization. It was immobilized on the complex of magnesium chloride with THF and on the complex of magnesium chloride with EtOH. Both supports were modified with $\mathrm{Et}_{2} \mathrm{AlCl}[23,29]$. All (co)polymerization reactions with the use of such catalytic systems were carried out in hexane for $30 \mathrm{~min}$, under $5 \mathrm{~atm}$. of ethylene. About $0.07 \mathrm{~g}$ of a supported catalyst and $8 \mathrm{mmol}$ of an activator were used.

The activity of previously investigated salen complexes of vanadium(IV) dichloride spectacularly increased after immobilization on the magnesium support [23]. Unfortunately, the activity of supported oxovanadium(IV) complexes was not much improved, although some changes in their catalytic behaviour in comparison with unsupported counterparts could be observed. Both the supported catalysts were found more active in conjunction with MAO then after activation by common alkylaluminium compound, and from among them trialkilaluminium compounds are better activators then $\mathrm{Et}_{2} \mathrm{AlCl}$ (Table 3). Their activity increased at higher polymerization temperatures. This is indicative for good thermal stability of the supported systems. Moreover, the supported systems similar to the unsupported one give linear polyethylene with a high melting temperature, in the range of $135.4-137.9^{\circ} \mathrm{C}$, and with high molecular weight. On the other hand, immobilization of a complex on a support affects the molecular weight distribution in the PE product. It is clearly lower in PE synthesized with the use of supported systems (1.4-2.3) than with the use of non-immobilized complexes (4.4-4.6), irrespective of the activator type employed ( $\mathrm{MAO}$ or $\mathrm{Me}_{3} \mathrm{Al}$ ). It can be said that single site catalyst is formed after complex immobilization. Immobilization of a complex also influenced the morphology of the polymer product, with some effect also observed for the type of the activator used (Fig. 9). The polymer granules produced by CatS2/MAO show porous surfaces and irregular shapes, alike for the polymer obtained from an unsupported system (Fig. 9a), although they are somewhat bigger. The same catalyst activated with $\mathrm{Me}_{3} \mathrm{Al}$ yields a 
Table 3 Ethylene polymerization catalyzed by supported catalysts

\begin{tabular}{|c|c|c|c|c|c|c|c|}
\hline Entry & Catalyst (g) & Activator (mmol) & Yield (g) & $\mathrm{T}_{\mathrm{m}}\left({ }^{\circ} \mathrm{C}\right)$ & $x(\%)$ & $\mathrm{M}_{\mathrm{w}} \cdot 10^{-3}(\mathrm{~g} / \mathrm{mol})$ & $\mathrm{M}_{\mathrm{w}} / \mathrm{M}_{\mathrm{n}}$ \\
\hline AB-38 & Cat-S1; 0.0687 & MAO & 1.121 & 137.9 & 43.9 & 864 & 2.3 \\
\hline $\mathrm{AB}-41^{\mathrm{a}}$ & Cat-S1; 0.0697 & MAO & 1.616 & 135.9 & 42.5 & nd & nd \\
\hline AB-39 & Cat-S1; 0.0746 & $\mathrm{Et}_{3} \mathrm{Al}$ & 0.320 & 137.2 & 39.0 & nd & nd \\
\hline AB-53 & Cat-S2; 0.0716 & MAO & 0.539 & 136.7 & 45.3 & 619 & 1.7 \\
\hline $\mathrm{AB}-54^{\mathrm{a}}$ & Cat-S2; 0.0786 & MAO & 1.226 & 135.9 & 47.8 & nd & nd \\
\hline $\mathrm{AB}-55^{\mathrm{a}}$ & Cat-S2; 0.0757 & $\mathrm{Me}_{3} \mathrm{Al}$ & 1.016 & 135.4 & 51.3 & nd & nd \\
\hline AB-61 & Cat-S2; 0.0740 & $\mathrm{Me}_{3} \mathrm{Al}$ & 0.617 & 136.5 & 44.2 & 624 & 1.4 \\
\hline $\mathrm{AB}-60^{\mathrm{a}}$ & Cat-S2; 0.0639 & $\mathrm{Et}_{2} \mathrm{AlCl}$ & 0.173 & 135.4 & 49.3 & nd & nd \\
\hline
\end{tabular}

Reaction conditions: $5 \mathrm{~atm}$ of ethylene, $30 \mathrm{~min}, 8 \mathrm{mmol}$ of activator, $50^{\circ} \mathrm{C}$ $n d$ not determned

${ }^{\mathrm{a}} 60^{\circ} \mathrm{C}$

polymer with definitely bigger grains of more regular shapes. The polymer obtained after the use of $\mathrm{Et}_{2} \mathrm{AlCl}$ as an activator, in turn, has the form of flat flakes.

The use of a higher 1-olefin in the reaction medium depresses the activity of both supported catalysts in relation to their performance in ethylene homopolymerization; that decline is more prominent for higher concentrations of 1-olefin. Immobilization was disadvantageous for a complex in efficient incorporation of a comonomer to the PE chain. At the same comonomer concentration of $0.40 \mathrm{~mol} / \mathrm{dm}^{3}$, the
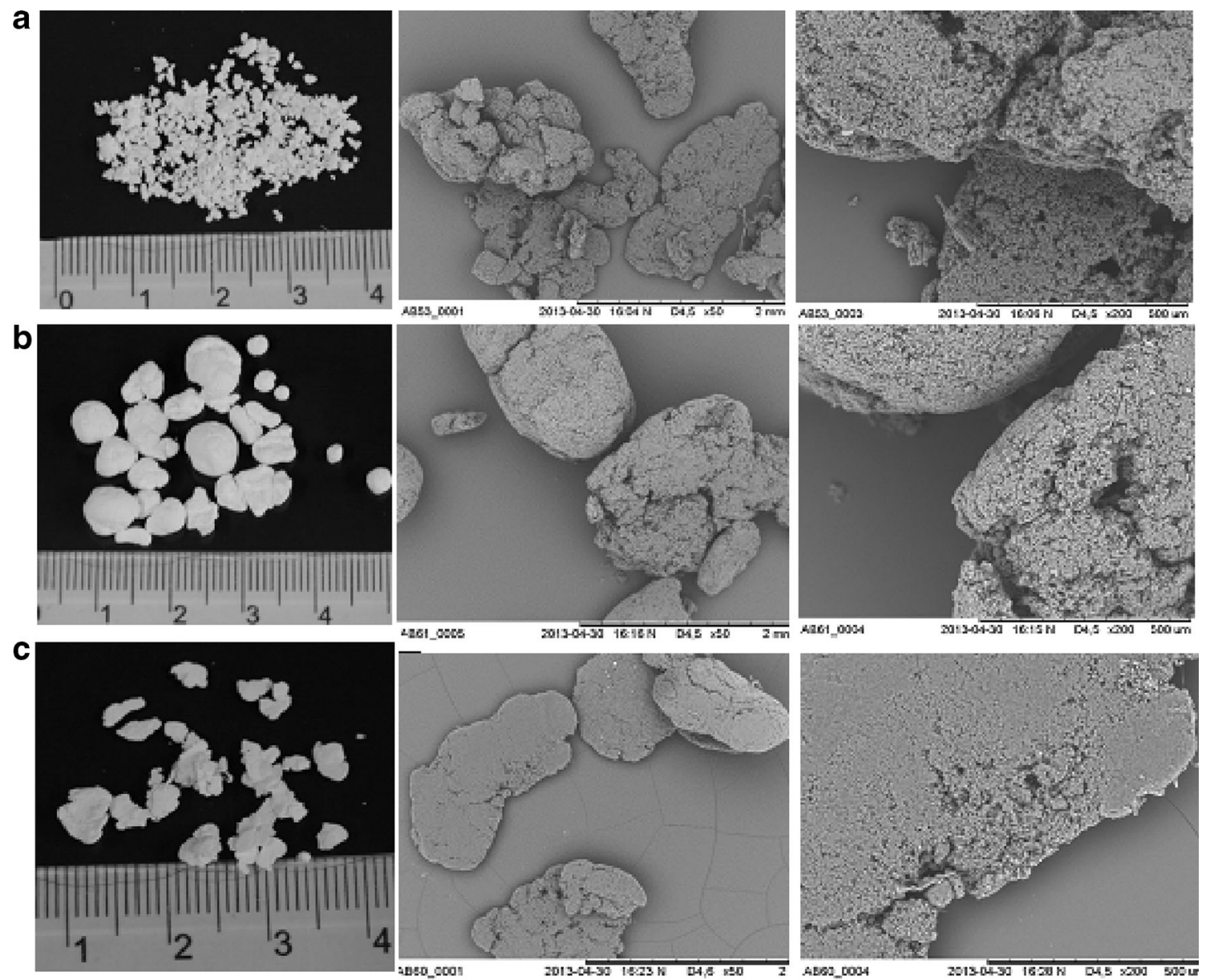

Fig. $9 \mathrm{SEM}$ imagines and photographs (on the left) of polyethylene obtained with a) Cat-S2/MAO, b) Cat-S2/Me $\mathrm{Al}_{3}$ and c) Cat-S2/Et ${ }_{2} \mathrm{AlCl}$; magnification $50 \times$ and $200 \times$ 
Table 4 Ethylene/1-octene copolymerization catalyzed by supported catalysts

\begin{tabular}{|c|c|c|c|c|c|c|c|c|c|}
\hline Entry & Catalyst (g) & Activator (mmol) & 1-octene (ml) & Yield (g) & $\mathrm{X}(\mathrm{mol} \%)$ & $\mathrm{T}_{\mathrm{m}}\left({ }^{\circ} \mathrm{C}\right)$ & $\chi(\%)$ & $\mathrm{M}_{\mathrm{w}} \cdot 10^{-3}(\mathrm{~g} / \mathrm{mol})$ & $\mathrm{M}_{\mathrm{w}} / \mathrm{M}_{\mathrm{n}}$ \\
\hline S46 & Cat-S1; 0.0718 & MAO & 5 & 1.223 & 0.1 & nd & nd & 740 & 1.60 \\
\hline S45 & Cat-S1; 0.0682 & MAO & 10 & 0.782 & 0.2 & 129.9 & nd & 705 & 1.55 \\
\hline S49 & Cat-S1; 0.0672 & MAO & 15 & 0.658 & 0.5 & 128.9 & 38.6 & 734 & 1.65 \\
\hline $\mathrm{S} 40$ & Cat-S1; 0.0677 & MAO & 20 & 0.117 & 0.7 & 129.4 & 37.0 & 613 & 1.54 \\
\hline $\mathrm{S} 50^{\mathrm{a}}$ & Cat-S1; 0.0736 & MAO & 15 & 0.974 & 0.9 & 126.6 & 37.9 & nd & nd \\
\hline $\mathrm{S} 51^{\mathrm{b}}$ & Cat-S1; 0.0717 & MAO & 15 & 0.491 & 0.2 & 131.8 & 35.4 & 1460 & 1.54 \\
\hline S56 & Cat-S2; 0.0784 & MAO & 10 & 0.138 & 0.6 & 129.5 & 43.1 & 488 & 1.52 \\
\hline S58 & Cat-S2; 0.0755 & MAO & 15 & 0.126 & 0.8 & 128.8 & 43.2 & 488 & 1.43 \\
\hline $\mathrm{S} 57$ & Cat-S2; 0.0624 & MAO & 20 & 0.041 & 1.6 & 127.6 & 38.8 & nd & nd \\
\hline S63 & Cat-S2; 0.0645 & $\mathrm{Me}_{3} \mathrm{Al}$ & 10 & 0.120 & 0.2 & 128.6 & 36.5 & 488 & 1.43 \\
\hline S62 & Cat-S2; 0.0673 & $\mathrm{Me}_{3} \mathrm{Al}$ & 15 & 0.012 & 0.2 & 127.1 & 40.5 & 513 & 1.59 \\
\hline
\end{tabular}

Reaction conditions: $5 \mathrm{~atm}$ of ethylene, $30 \mathrm{~min}, 8 \mathrm{mmol}$ of activator, $50{ }^{\circ} \mathrm{C}$ nd not determned

${ }^{\mathrm{a}} 60^{\circ} \mathrm{C}$

${ }^{\mathrm{b}} 40{ }^{\circ} \mathrm{C}$

copolymer produced by [VO(acacen)] complex contained $5.26 \mathrm{~mol} \%$ (Table 2, run 26) whereas in the presence of supported catalysts the copolymers having less than $1 \mathrm{~mol} \%$ of 1-octene units were obtained (Table 4, runs S45, S56, S63). The obtained copolymers had different properties than homopolymers produced by the same catalytic systems. The principal differences include lower melting points, lower contents of crystalline phase and reduced molecular weights in relation to homopolymers.

Higher temperatures improve the catalyst activity, reduce molecular weights and melting points of copolymers (S49, S50 and S51). Increasing temperature also gives a nearly linear growth in 1-octene incorporation to the polyethylene chain which may result from the fact that ethylene solubility in the reaction medium declines at higher reaction temperatures.

\section{Conclusions}

It is the first time that the catalytic performance of oxovanadium(IV) complexes with [ONNO]-chelating ligands such as salen, acacen, aceten and acetph in ethylene homoand copolymerization was described. The studies show that the oxovanadium catalysts have the ability to produce polyethylene with high molecular weight and ability to copolymerize ethylene with 1-olefins to produce copolymers with high comonomer incorporation and high molecular weights which is required for this type of catalysts. The activity of these complexes is moderate and it increased in the line: $[\mathrm{VO}($ salen $)]<[\mathrm{VO}$ (acetph) $]<[\mathrm{VO}$ (aceten) $]<[\mathrm{VO}$ (acacen) $]$. The highest incorporation ability is shown by the salen complex of oxovanadium which can suggest that the methyl substituent at the imine group carbon atom slightly hinders the comonomer incorporation. The catalyst activity, 1-octene incorporation and copolymers properties are dependent on the comonomer feeds, polymerization temperature and $\mathrm{Al} / \mathrm{V}$ molar ratio. The copolymer yield, melting point, crystallinity and molecular weight decreases with increasing of 1-octene concentration, while comonomer incorporation rises. Only in the case of copolymerization catalyzed by salen complex the presence of comonomer in the polymerization feed result in a somewhat higher polymer molecular weight.

Immobilization of [ $\mathrm{VO}($ acacen$)]$ on magnesium supports improved thermal stability of the catalysts and also slightly enhanced their catalytic activity. However, immobilization failed to maintain a high potential for comonomers incorporation.

Acknowledgment The presented work in the range of (co)polymerization and polymer characterization was financially supported by the Polish National Science Center: grant № N N209 140840 within 2011-2014. The authors thank E. Myrczek and A. Janowski for providing [VO(salen)] and [VO(acacen)], respectively.

Open Access This article is distributed under the terms of the Creative Commons Attribution License which permits any use, distribution, and reproduction in any medium, provided the original author(s) and the source are credited.

\section{References}

1. Nomura K, Zhang S (2011) Chem Rev 111:2342-2362

2. Wu JQ, Li YS (2011) Coord Chem Rev 255:2303-2314

3. Hagen H, Boersma J, van Koten G (2002) Chem Soc Rev 31: $357-364$

4. Barabanov AA, Semikolenova NV, Bukatov GD, Matsko MA, Zakharov VA (2012) J Polym Res 19(9998):1-9

5. Białek M, Bisz E (2013) J Polym Res 20(164):1-9 
6. Addisson E, Deffieux A, Fontanille M (1993) J Polym Sci A Polym Chem 3:831-839

7. Czaja K, Bialek M (1998) Macromol Rapid Commun 19:163-166

8. Ma Y, Readron D, Gambarotta S, Yap G (1999) Organometallics 18: 2773-2781

9. Makio H, Terao H, Iwashita A, Fujita T (2011) Chem Rev 111:2363-2449

10. Wu JQ, Pan L, Li YG, Liu SR, Li YS (2009) Organometallics 28: $1817-1825$

11. Tomov AK, Gibson VC, Zaher D, Elsegood MRJ, Dale SH (2004) Chem Commun 1956-1957

12. Mu JS, Wang YX, Li BX, Li YS (2011) Dalton Trans 40: 3490-3497

13. Tang LM, Wu JQ, Duan YQ, Pan L, Li YG, Li YS (2008) J Polym Sci A Polym Chem 46:2038-2048

14. $\mathrm{Xu} \mathrm{BC}, \mathrm{Hu} \mathrm{T}$, Wu JQ, Hu NH, Li YS (2009) Dalton Trans $8854-8863$

15. Zhang SW, Zhang GB, Lu LP, Li YS (2013) J Polym Sci A Polym Chem 51:844-854

16. Wang W, Nomura K (2006) Adv Synth Catal 348:743-750

17. Redshaw C, Warford L, Dale SH, Elsegood MRJ (2004) Chem Commun 1954-1955

18. Lorber C, Wolff F, Choukroun R, Vendier L (2005) Eur J Inorg Chem 2850-2859

19. Soshnikov IE, Semikolenova NV, Shubin AA, Bryliakov KP, Zakharov VA, Redshaw C, Talsi EP (2009) Organometallics 28: 6714-6720

20. Soshnikov IE, Semikolenova NV, Bryliakov KP, Shubin AA, Zakharov VA, Redshaw C, Talsi EP (2009) Macromol Chem Phys 210:542-548

21. Homden DM, Redshaw C, Hughes DL (2007) Inorg Chem 46: 10827-10839

22. Białek M, Czaja K (2008) J Polym Sci A Polym Chem 46: 6940-6949
23. Białek M, Pietruszka A (2009) J Polym Sci A Polym Chem 47:34803489

24. Sudoł M, Czaja K, Białek M (2000) Polimery (W) 45:405-410

25. Widman G, Riesen R (1987) In: Oehme F (ed) Thermal analysis: terms, methods, applications. Dr Alfred Hüthing: Verlag, Heidelberg, p 23

26. Czaja K, Sacher B, Białek M (2002) J Therm Anal Calorim 67: $547-554$

27. Farmer RL, Urbach FL (1970) Inorg Chem 9:2562-2567

28. Boucher LJ, Tynan EC (1968) Inorg Chem 7:731-736

29. Białek M, Garłowska A, Liboska O (2009) J Polym Sci A Polym Chem 47:4811-4821

30. Tsuchchimoto M, Kasahara R, Nakajima K, Kojami M, Ohba S (1999) Polyhedron 18:3035-3039

31. Riley PE, Pecoraro VL, Carrano CJ, Bonadies JA (1986) Inorg Chem $25: 154-160$

32. Bruins D, Weaver DL (1970) Inorg Chem 9:130-135

33. Kurzak K, Ejsmond K, Koprek K (2011) Acta Crystallogr C67: $\mathrm{m} 287-\mathrm{m} 289$

34. Wu JQ, Li BX, Zhang SW, Li YS (2010) J Polym Sci A Polym Chem 48:3062-3072

35. Xu G, Ruckenstein E (1998) Macromolecules 31:4724- 4729

36. Li H, Niu Y (2011) J Appl Polym Sci 121:3085-3092

37. Kakinuki K, Fujiki M, Nomura K (2009) Macromolecules 42:4585-4595

38. Galland GB, Seferin M, Mauler RS, Dos Santos JHZ (1999) Polym Int 48:660-664

39. Jungling S, Koltzenburg S, Mülhaupt R (1997) J Polym Sci A Polym Chem 35:1-8

40. Wigum H, Tangen L, Støvneng JA, Rytter E (2000) J Polym Sci A Polym Chem 38:3161-3172

41. Bruaseth I, Rytter E (2003) Macromolecules 36:3026-3034

42. Mu JS, Shi XC, Li YS (2011) J Polym Sci A Polym Chem 49:2700-2708

43. Müller A, Arnal ML (2005) Prog Polym Sci 30:559-603 